\title{
Pathways of flower infection and pollen-mediated dispersion of Pseudomonas syringae pv. actinidiae, the causal agent of kiwifruit bacterial canker
}

\author{
Irene Donati ${ }^{1}$, Antonio Cellini', Giampaolo Buriani $\mathbb{1}^{1}$, Sofia Mauri ${ }^{1}$, Callum Kay², \\ Gianni Tacconi ${ }^{3}$ and Francesco Spinelli ${ }^{1}$
}

\begin{abstract}
Flowers can provide a protected and nutrient-rich environment to the epiphytic microflora, thus representing a sensible entry point for pathogens such as Pseudomonas syringae pv. actinidiae (Psa). This bacterium can colonize both male and female Actinidia flowers, causing flower browning and fall, and systemic invasion of the host plant, eventually leading to its death. However, the process of flower colonization and penetration into the host tissues has not yet been fully elucidated. In addition, the presence of Psa in the pollen from infected flowers, and the role of pollination in the spread of Psa requires confirmation.

The present study employed a Psa strain constitutively expressing the fluorescent GFPuv protein, to visualize in vivo flower colonization. Microscopy observations were performed by means of confocal laser scanning and wide-field fluorescent microscopy, and were coupled with the study of Psa population dynamics by quantitative PCR (q-PCR). The pathogen was shown to colonize stigmata, move along the stylar furrow, and penetrate the receptacles via the style or nectarhodes. Once the receptacle was invaded, the pathogen migrated along the flower pedicel and became systemic. Psa was also able to colonize the anthers epiphytically and endophytically. Infected male flowers produced contaminated pollen, which could transmit Psa to healthy plants. Finally, pollinators (Apis mellifera and Bombus terrestris) were studied in natural conditions, showing that, although they can be contaminated with Psa, the pathogen's transmission via pollinators is contrasted by its short survival in the hive.
\end{abstract}

\section{Introduction}

Among the production constraints of kiwifruit, the bacterial canker, caused by Pseudomonas syringae pv. actinidiae (Psa), has been the major limiting factor in the main growing areas worldwide since its pandemic outbreak in $2008^{1-3}$. The disease affects various species of the genus Actinidia, including the two most important varieties for

\footnotetext{
Correspondence: Francesco Spinelli (francesco.spinelli3@unibo.it)

'Department of Agricultural and Food Sciences - DISTAL, Alma Mater Studiorum_University of Bologna, viale Fanin 44, 40127 Bologna, Italy 2ZESPRI GLOBAL Supply, 400 Maunganui Road, Mount Maunganui, New Zealand

Full list of author information is available at the end of the article.
}

commercial purposes, A. chinensis var. deliciosa and $A$. chinensis var. chinensis ${ }^{4-6}$. In Italy, the first outbreak of bacterial canker was reported in $1994^{7}$, but serious economic damage started being observed with the spread of a highly virulent pathogen, named biovar 3 , genetically separated from previously identified biovars ${ }^{8-12}$.

Many aspects of Psa biology and epidemiology still require in-depth investigation. Among them, the elucidation of the primary entry points and mechanisms of spread from plant to plant are of crucial importance. A few short communications have listed plant organs in which the pathogen was detected ${ }^{13,14}$. However, the detection of an endophytic pathogen within a specific

\section{(c) The Author(s) 2018}

(c) (i) Open Access This article is licensed under a Creative Commons Attribution 4.0 International License, which permits use, sharing, adaptation, distribution and reproduction cc) in any medium or format, as long as you give appropriate credit to the original author(s) and the source, provide a link to the Creative Commons license, and indicate if changes were made. The images or other third party material in this article are included in the article's Creative Commons license, unless indicated otherwise in a credit line to the material. If material is not included in the article's Creative Commons license and your intended use is not permitted by statutory regulation or exceeds the permitted use, you will need to obtain permission directly from the copyright holder. To view a copy of this license, visit http://creativecommons.org/licenses/by/4.0/. 
plant organ, not accounting for its ability to move through plant tissues, does not imply a primary apoplastic invasion through the same organ. In addition, these studies were mainly performed in A. chinensis var. chinensis, allowing the isolation of Psa from a number of natural openings and wounds such as symptomatic lenticels, lesion margins, buds, fruit stalks, leaf petioles, and flowers ${ }^{13,14}$.

Typical flower symptoms consist of browning of petals and sepals in early stages of infection. Subsequently, Psainfected blossoms may wither before opening, or fall off soon after fruit set. However, such symptoms are not specific to Psa, being similar to those of blossom blight caused by Pseudomonas viridiflava and P. syringae pv. syringae ${ }^{15-18}$.

Although female flowers can provide bacteria with a protected and nutrient-rich environment ${ }^{14}$, the process of flower colonization by Psa and its penetration into the host tissues has not been yet fully elucidated. The precise knowledge of the mechanisms and time of the invasion of the host tissue is essential to understand the disease cycle and to develop effective control strategies. Despite the fact that more than 100 bacterial species are known to be plant pathogens, pollen-mediated transmission of bacterial pathogens has only been postulated for Xanthomonas arboricola pv. juglandis ${ }^{19,20}$, Erwinia amylovora $^{21}$ and Pseudomonas syringae ${ }^{22}$, even though they are not the only pathogens which may infect flowers, and compelling evidence for pollen-mediated bacterial spread in real conditions is still missing. In Erwinia amylovora, which is the most widely studied bacterial pathogen leading to systemic infection by flower colonization ${ }^{23,24}$, the production of contaminated pollen by infected flowers was achieved only in experimental conditions, by applying a highly concentrated $\left(10^{8}\right.$ cells $\left.\mathrm{mL}^{-1}\right)$ bacterial suspension directly on anthers ${ }^{21}$, while the production of contaminated pollen in natural conditions has never been described.

In addition, E. amylovora and other bacterial pathogens may rely on pollinating insects for secondary spread ${ }^{25,26}$. Several insect species, such as honeybees (Apis mellifera) and bumblebees (Bombus spp.), contribute to kiwifruit pollination ${ }^{27}$. However, although Actinidia spp. flowers are fragrant, their attractivity to pollinators is poor, and some of their characteristics (pendulous position, high pollen:ovule ratio, large multibranched stigmatic surfaces, scarce production of nectar) suggest that wind may be an important agent of pollen transfer ${ }^{28,29}$.

To obtain export-quality fruit, more than 2000 pollen grains should reach the stigma leading to fruits with $1000-1400$ viable seeds ${ }^{27}$. Since pollination dictates the size and the quality of the kiwifruit berries, pollen collection and artificial pollination have become a widespread practice to enhance fruit production and size $^{30,31}$.
Therefore, understanding the importance of pollen and pollination for the dissemination of Psa from plant to plant is a crucial step for the control of bacterial canker.

Several studies showed that Actinidia spp. pollen or commercial pollen preparations can be contaminated by $\mathrm{Psa}^{13,32-36}$. Preliminary results on the pollen-mediated vectoring of Psa were reported by Tontou et al. ${ }^{37}$. However, limited information is currently available on a number of crucial aspects regarding the actual presence of Psa in the pollen in field conditions, and the consequent epidemiological risk. In fact, although the viable Psa population on pollen grains was quantified in some experiments, crucial pieces of information (such as the minimal Psa population on pollen needed to effectively transfer Psa on flowers, the infection threshold of flowers, or the overall pollen-mediated infection efficacy) are still missing.

The present study elucidates the different phases of flower colonization by Psa till the systemic invasion of the host plant. Moreover, the effect of infection on fruit production and colonization by Psa was evaluated. Finally, this study provides the first evidence on the production of infected pollen by diseased male plants, and the role of pollen and pollination in the dissemination of Psa.

The colonization of the different flowers parts was studied in vivo and real-time by combining the use of a green fluorescent protein (GFP)-labeled Psa strain (CFBP7286-GFPuv) with fluorescent stereomicroscopy and confocal laser scanning microscopy. These methodologies allowed the univocal identification of the bacteria and the in vivo, non-invasive observation of plant tissues ${ }^{13,24}$. With the possible exception of fire blight ${ }^{21,38}$ (E. amylovora), this is the first, non-speculative report of pollen-mediated transmission of a phytopathogenic bacterium.

\section{Materials and methods Biological material}

Experiments in controlled conditions were performed on kiwifruit cultivars Hayward (female, A. chinensis var. deliciosa), Tomuri (male, A. chinensis var. deliciosa), Hort16A (female, A. chinensis var. chinensis) and CK2 (male, A. chinensis var. chinensis), using 4-year-old potted plants maintained in plastic pots $(40 \mathrm{~cm}$ diameter) with a mixture of peat and sand $(1: 1, \mathrm{v} / \mathrm{v})$. Standard irrigation and fertilization was applied. As mineral fertilizer, PolyFeed (16N-8P-32K) by Fertica S.A. was used (18 g per plant applied two times). During the experiments, the plants were kept in glasshouse conditions under natural light. Temperature and relative humidity were, respectively, $22-24{ }^{\circ} \mathrm{C}$ and $70-80 \%$. After inoculation, the relative humidity was raised to $100 \%$ for the following $48 \mathrm{~h}$.

The Psa strain CFBP7286-GFPuv was used for artificial inoculation. This genetically engineered strain, retaining 
the virulence of the corresponding wild type (CFBP7286, biovar 3), expresses a green fluorescent protein and kanamycin resistance ${ }^{13}$. The inocula were prepared by cultures grown in liquid Luria-Bertani medium under moderate shaking at $27^{\circ} \mathrm{C}$, then resuspending the bacteria in $10 \mathrm{mM} \mathrm{MgSO}_{4}$. The titer of bacterial suspensions was determined by plating 10- $\mu \mathrm{L}$ drops of serial 1:10 dilutions on Luria-Bertani medium containing $15 \mathrm{~g} \mathrm{~L}^{-1}$ of agar amended with cyclohexamide $\left(100 \mathrm{mg} \mathrm{L}^{-1}\right)$. In experiments using infected samples from commercial fields, Psa identity in serial dilutions was confirmed by $\mathrm{q}-\mathrm{PCR}^{39}$.

\section{Experimental inoculation of Actinidia spp. flowers}

Several inoculation methods of a Psa suspension at $10^{6}$ colony-forming units (cfu) $\mathrm{mL}^{-1}$ were used for each plant cultivar: (i) spraying the whole flower, (ii) dipping the stigmata or anthers in the bacterial suspension, or (iii) pipetting $20 \mu \mathrm{L}$ of the same bacterial suspension on the calyx. Sixty flowers were inoculated with each of the three different inoculation methods. Water-treated flowers were used as the control. All the female flowers were artificially pollinated $6 \mathrm{~h}$ before inoculation.

The tissues (stigmata/anthers, ovarium, and other flower parts) of six spray-inoculated flowers were separated at $0,3,24,48,72,96$, and $120 \mathrm{~h}$ after inoculation, and the epiphytic Psa population was measured on them. The samples were vigorously washed for $5 \mathrm{~min}$ in $5 \mathrm{~mL}$ of sterile $10 \mathrm{mM} \mathrm{MgSO}_{4}$ solution.

To assess endophytic Psa populations, the same tissue samples were surface-sterilized by washing in ethanol (70\%, $3 \mathrm{~min})$ and $\mathrm{NaOCl}(0.1 \%, 3 \mathrm{~min})$, followed by two rinses in sterilized water. Then they were homogenized in $10 \mathrm{mM} \mathrm{MgSO}_{4}$ and the bacterial population was assessed as previously described. The complete efficacy of the sterilization method was confirmed by comparing the epiphytic Psa population of unsterilized and sterilized organs. To assess Psa endophytic population in the flower-bearing cane (i.e., stalk), a wood section of $1 \mathrm{~cm}$ in length on either side of the flower pedicel was excised and analyzed. Each experiment was repeated three times.

\section{Psa presence on flowers and pollen in infected orchards}

The sampling of flowers from male and female plants was performed in three commercial kiwifruit orchards in Faenza region, Italy $\left(44^{\circ} 17^{\prime} 00.0^{\prime \prime} \mathrm{N} 11^{\circ} 53^{\prime} 00.0^{\prime \prime} \mathrm{E}\right)$, with a disease incidence of $50 \%$ (assessed as the proportion of vines showing symptoms).

The incidence of Psa and other kiwifruit pathogens (P. syringae pv. syringae, $P$. viridiflava) was determined on 600 samples of $A$. chinensis var. chinensis (cv. Hort16A) and $A$. chinensis var. deliciosa (cv. Hayward) female flowers showing browning symptoms. On flowers infected by Psa, the bacterial population of this pathogen was quantified.
The natural occurrence of Psa on asymptomatic male flowers and pollen was determined on closed $(\mathrm{BBCH}$ 53-55) and open flower samples (BBCH 60) (100 for each type and for the two A. chinensis varieties).

Anthers (from samples before dehiscence stage in closed flowers) or pollen (from fully open flowers) were aseptically separated from the remaining tissues of tenflower samples. Before dissection of closed flowers, the external surface was sterilized as previously described. Pollen was washed with $20 \mathrm{~mL}$ of sterile water for $15 \mathrm{~min}$ on a rotary shaker at $120 \mathrm{rpm}$ until full rehydration. Subsequently, the samples were precipitated by centrifugation $(90 \mathrm{~s}$ at $10,000 \times g)$, and the supernatant was used for bacterial enumeration.

Pollen germination was assessed as the percentage of granules emitting a tube after $5 \mathrm{~h}$ at $25^{\circ} \mathrm{C}$ under shaded light, in a medium containing $10 \%$ sucrose and $15 \mathrm{~g} \mathrm{~L}^{-1}$ agar.

In 2016, to verify the possibility of contamination of pollen via an endophytic invasion, three 1-year -old $A$. chinensis var. chinensis potted male vines were sprayinoculated at bud break with CFBP7286-GFPuv $\left(10^{8} \mathrm{CFU}\right.$ $\mathrm{mL}^{-1}$ in $10 \mathrm{mM} \mathrm{MgSO}$ ). Plants were kept in controlled conditions till flower development. At the beginning of flowering, ten opening flowers were collected from each plant and anthers were aseptically excised. Presence of Psa was assessed by serial dilution plating and q-PCR, as previously described.

\section{Flower colonization by pollen-vectored Psa}

Pollen samples $(0.5 \mathrm{~g})$ of $A$. chinensis var. chinensis (cvs. CK2 and Belen) and A. chinensis var. deliciosa (cv. Tomuri) were artificially inoculated with $1.5 \mathrm{~mL}$ of a suspension of CFBP7286-GFPuv $\left(10^{7} \mathrm{CFU} \mathrm{mL}^{-1}\right.$ in 10 $\mathrm{mM} \mathrm{MgSO}_{4}$ ) obtained from fresh cultures in liquid LB medium. The wet contaminated pollen was dried at room temperature for $72 \mathrm{~h}$. For each pollen sample, the bacterial population was monitored over 5 days. Before using contaminated pollen for inoculation of flowers, Psa population was determined and adjusted to $4.1 \times 10^{6}$ cfu $\mathrm{g}^{-1}$ by adding uncontaminated pollen. Pollen viability and germination were assessed as previously described.

Hand-pollination was performed on 4-year-old A. chinensis var. chinensis (cv. Hort16A) and A. chinensis var. deliciosa (cv. Hayward) potted plants, by dusting Psa-free pollen with a wet brush on each flower. In a second group of plants, infected pollen was used instead. Nine plants divided in three replicates were used for each treatment. Endophytic and epiphytic Psa populations were determined 5 and 10 days after inoculation in the different flower organs and in the bearing cane. The same experiments were repeated using naturally infected $A$. chinensis var. chinensis (cvs. CK2 and Belen) and A. chinensis var. deliciosa (cv. Tomuri) pollen. In this case, the Psa population was determined and adjusted to $1.2 \times 10^{4} \mathrm{cfu} \mathrm{g}^{-1}$. 


\section{Pollen-mediated vectoring of Psa in natural conditions}

To mimic the pollen-mediated vectoring of Psa in natural conditions, flowering branches of male A. chinensis var. chinensis (cv. Belen) were detached from infected plants in a commercial orchard. Twelve branches were transferred in controlled semi-field conditions, maintained in water and placed for 5 days in proximity $(1 \mathrm{~m})$ to nine healthy $A$. chinensis var. chinensis (cv. Hort16A) potted plants divided in three replicates. To prevent uncontrolled diffusion of Psa in the environment by insects or water leach, plants were placed under a tunnel built with anti-aphid net (Antiafide 20/10 Mesh 50, Artes Politecnica s.r.l, Vicenza, Italy). The tunnel dimensions were $12 \times 3.50 \times 5.50 \mathrm{~m}$. The floor was covered with an impermeable plastic film.

Psa load on naturally infected pollen was quantified as previously described, and it resulted to be $3 \times 10^{6} \mathrm{cfu} \mathrm{g}^{-1}$.

A similar experiment was repeated on $A$. chinensis var. deliciosa (cv. Hayward) using infected Tomuri vines.

Incidence was calculated as the percentage of flowers presenting a systemic endophytic Psa population inside the stalk (i.e., flower-bearing canes). Epiphytic and endophytic Psa populations were determined 5 and 10 days after inoculation in the different flower organs and in the bearing cane.

\section{Systemic colonization of the host plant upon flower inoculation}

To monitor the dynamics of systemic invasion upon flower infection, on six A. chinensis var. chinensis (cv. Hort16A) and six A. chinensis var. deliciosa (cv. Hayward) potted plants, a single flower cluster per plant was inoculated by using pollen from male plants of the same variety (cvs. Belen and Tomuri, respectively), contaminated by CFBP7286-GFPuv $\left(4.1 \times 10^{4} \mathrm{CFU} \mathrm{g}^{-1}\right)$.

The evolution of flower symptoms, fruit set, development, and fall were monitored weekly. The endophytic migration of Psa was assessed 4 months after inoculation. Tissue samples were taken from cane tops, grafting points, rootstock wood and roots. Tissue samples were surface-sterilized by washing in ethanol (70\%, $3 \mathrm{~min}$ ) and $\mathrm{NaOCl}(0.1 \%, 3 \mathrm{~min})$, followed by two rinses in sterilized water. Successively, they were homogenized in $10 \mathrm{mM}$ $\mathrm{MgSO}_{4}$ and the bacterial population was assessed as previously described. The experiment was repeated twice.

\section{Psa vectoring by pollinators}

The experiments were performed in 2 consecutive years in commercial orchards located in the area of Latina $\left(41^{\circ}\right.$ $28^{\prime} 03.35^{\prime \prime} \mathrm{N} 12^{\circ} 54^{\prime} 13.32^{\prime \prime} \mathrm{E}$ ), with 15 to $20 \%$ disease incidence (assessed as the percentage of vines showing symptoms). Five commercial bumblebee hives (Natupol ${ }^{\circledR}$ Koppert B.V., The Netherlands) were placed in each orchard at $75 \%$ flowering. Five days after beehive positioning, bumblebee capture was performed for 3 consecutive days. Each sampling consisted of ten bumblebees captured after return to the beehive. Pollen harvested by bumblebees was also collected and analyzed. Psa was isolated and identified as previously described for other substrates.

To verify Psa survival on honeybees and in honeybee hives, a set of tubes was closed with microbiological filters. In each tube, a dead insect, $0.2 \mathrm{~g}$ wax, or $20 \mathrm{mg} A$. chinensis var. deliciosa (cv. Tomuri) pollen were placed, after inoculation with $10 \mu \mathrm{L}$ of a Psa suspension with a bacterial titer of $10^{6}, 10^{8}$ or $10^{10} \mathrm{cfu} \mathrm{mL}^{-1}$. The biological samples were maintained in a honeybee hive, together with a data logger recording temperature and relative humidity, and Psa population was monitored.

\section{Microscopy}

Following inoculation with bacterial suspensions or with artificially contaminated pollen, Psa distribution over flower tissues, and migration through them was monitored by microscopical observation.

Sample preparation and initial observations were performed using a motorized Nikon SMZ25 (Nikon, Tokyo, Japan) with a zoom ratio of 25:1 (zoom range: $0.63 \times$ $31.45 \times$ ) fitted with a BHS (GHS) filter set. The GHS filter set (excitation light $450-490 \mathrm{~nm}$, emission $510 \mathrm{~nm}$ ) was used to visualize the GFPuv-labeled bacteria.

Optical sections were obtained with a Nikon C1-S (Nikon, Tokyo, Japan) confocal laser scanning microscope (CLSM) and equipped with an Argon laser. A 40, 60 and $100 \times$ Nikon PlanApo objectives and the BHS (GHS) filter set were used for image acquisition. Images were acquired and analyzed by the NIS-Elements C Microscope Imaging Software.

\section{Statistical analysis}

Psa populations, at different time points and in different A. chinensis flowers parts, were analyzed by one-way analysis of variance (ANOVA) followed by means separation with Fisher's least significant difference (LSD, $P<0.05)$. Incidence of male and female flowers contaminated by Psa in different $A$. chinensis variety was analyzed by $Z$-test $(P<0.05)$. For statistical analysis the software STATISTICA 7.0 (StatSoft Inc, Tulsa, USA) was used.

\section{Results}

Population of Pseudomonas syringae pv. actinidiae on Actinidia spp. flowers

Psa was able to establish a detectable population on all the flowers parts of both $A$. chinensis var. chinensis and $A$. chinensis var. deliciosa female flowers (Fig. 1a, b). The highest population was observed on stigmata and styles with an average value of $3.6 \pm 2.1 \times 10^{5} \mathrm{cfu}$ for the whole 

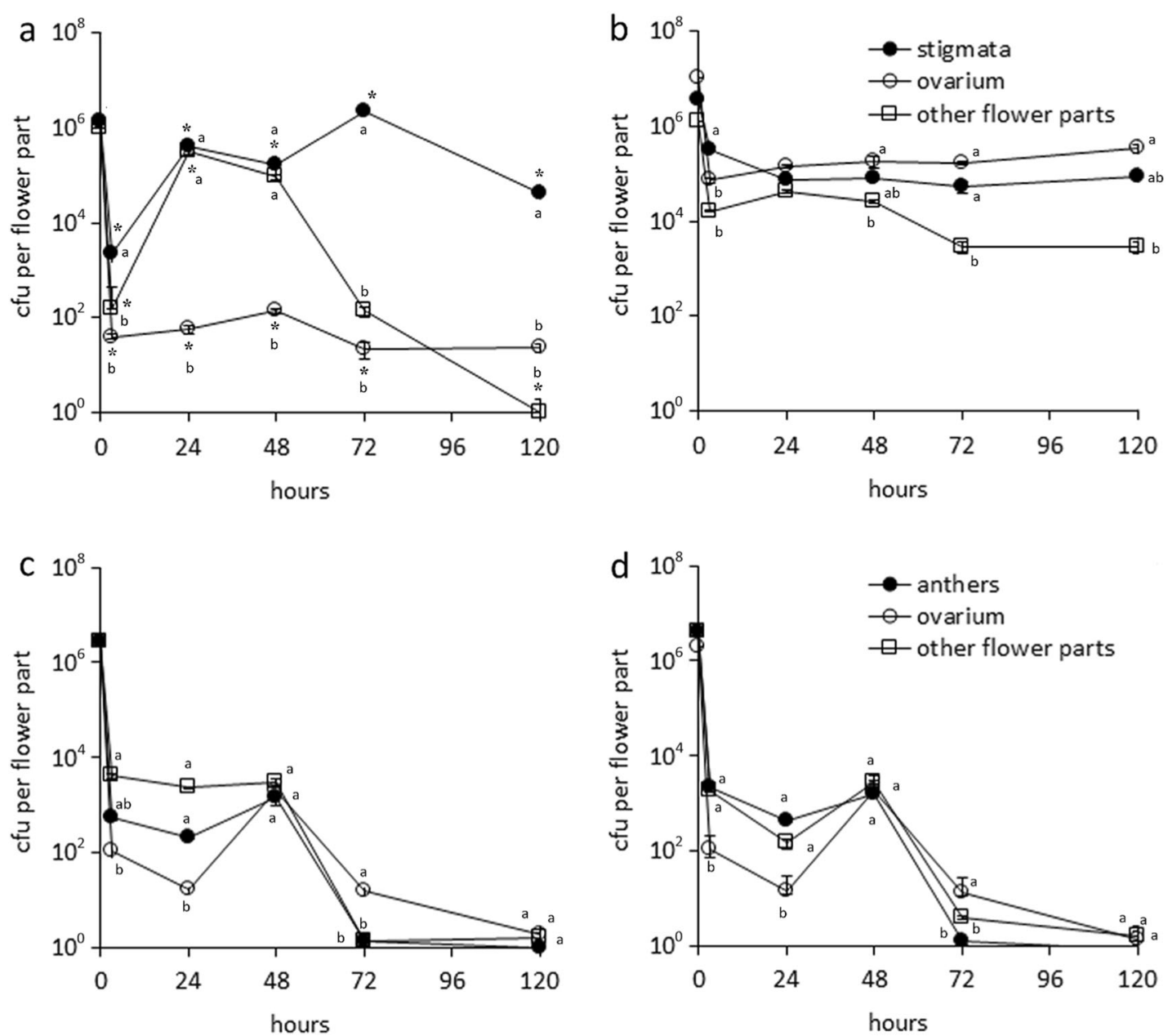

Fig. 1 Evolution of Pseudomonas syringae pv. actinidiae (Psa) population over time in different Actinidia chinensis flower parts: a Female A. chinensis var. deliciosa, $\mathbf{b}$ female $A$. chinensis var. chinensis, $\mathbf{c}$ male $A$. chinensis var. deliciosa, and $\mathbf{d}$ male $A$. chinensis var. chinensis. Inoculation was performed by spraying flowers with a Psa (CFBP7286) suspension at a concentration of $10^{6} \mathrm{cells} \mathrm{mL}^{-1}$. Standard error is shown $(n=6$ for each time point). Different letters indicate significant differences among flower parts within each variety at LSD test $(P=0.05)$. In female flowers, asterisk indicates significant differences of Psa population between the same flower part of A. chinensis var. chinensis and A. chinensis var. deliciosa (LSD test, $P=0.05)$. The same analysis performed on male flowers did not reveal any significant difference among varieties

duration of the experiment. Other flower parts, in $A$. chinensis var. deliciosa, hosted such a high population only transiently. In contrast, in A. chinensis var. chinensis, Psa population constantly ranged between $10^{4}$ and $10^{6}$ on all flower tissues (Fig. 1a, b). On male flowers, Psa attained a lower population, showing a substantial decrease after $48 \mathrm{~h}$ corresponding with tissue senescence (especially anthers; Fig. 1c, d). No differences were observed between A. chinensis var. chinensis and $A$. chinensis var. deliciosa male flowers.

The inoculation methods influenced the endophytic colonization of the different flower organs. Within floral tissues, the pathogen population was generally higher in A. chinensis var. chinensis tissues than in A. chinensis var. deliciosa (Supplementary Fig. S1). After inoculation by spray, the highest bacterial populations were found in the flower stalk. In female flowers, the dipping-inoculation of the stigma led to colonization of the flower pedicel and stalk only in A. chinensis var. chinensis, whereas on $A$. chinensis var. deliciosa, Psa was isolated from those flower parts only occasionally. After the infection of the ovarium, the pathogen was mainly found in the gynoecium and calyx (Supplementart Fig. S1).

On male flowers, the isolation of the pathogen from the flower tissues was achieved only after spray inoculation. Also on male flowers, the highest Psa populations were isolated from $A$. chinensis var. chinensis.

After spray inoculation, $75 \%$ of $A$. chinensis var. chinensis and $53 \%$ of $A$. chinensis var. deliciosa female flowers were infected stricto sensu (i.e., they harbored an 

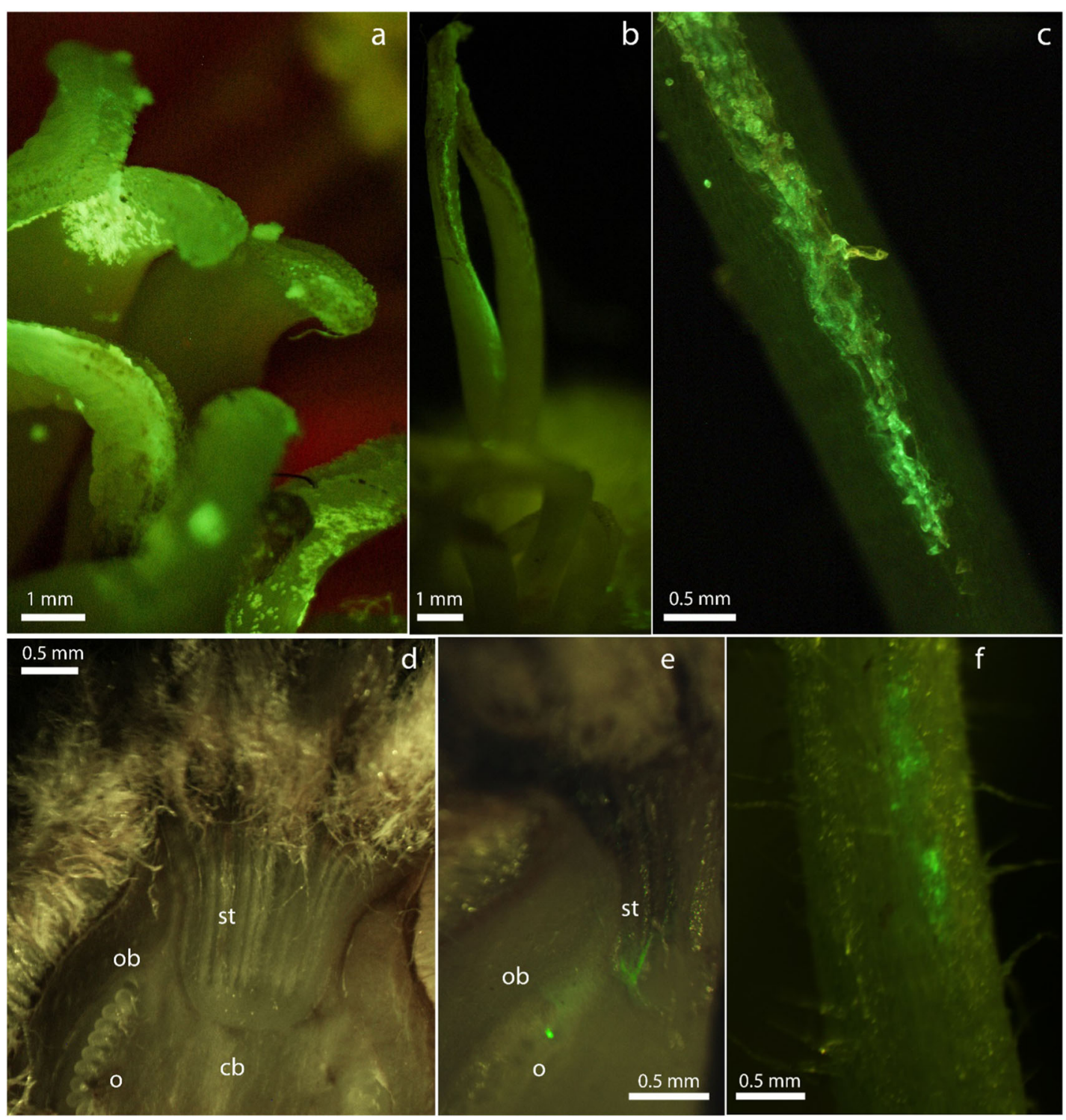

Fig. 2 Fluorescent stereomicroscope photographs of Actinidia chinensis var. deliciosa flowers contaminated by Pseudomonas syringae pv. actinidiae (Psa) expressing a green fluorescent protein (CFBP7286-GFPuv). Inoculation was performed by pollinating stigmas of each flower with pollen contaminated by GFPuv-Psa. Bright green fluorescent emission is due to Psa CFBP7286-GFPuv colonization of tissues. Photographs were taken $24 \mathrm{~h}$ after inoculation $(\mathbf{a}, \mathbf{b}, \mathbf{c})$ or 6-9 days after inoculation (d, e, $\mathbf{f}$. a Stigma coated by contaminated pollen grains. b, c Psa CFBP7286-GFPuv migration along the whole stylar furrow to the ovarium (d-e). $\mathbf{d}$ Healthy ovarium. e Infected ovarium. The pathogen reached the ovarium via the styles (st). Central placenta vascular bundle (cb), ovary wall vascular bundle (ob) and ovules (o) are visible. Fluorescence is associated to the vascular bundles. $\mathbf{f}$ Flower pedicel, showing the high contamination by CFBP7286-GFPuv leading to a systemic invasion of from the ovarium into the flowerbearing cane. Bar measure is reported in each panel

endophytic Psa population). The infection of male flowers occurred, in both species, in approximately $60 \%$ of the inoculated samples.

The microscopic observations show that the bacterium, after the colonization of the stigma, moves along the style and reaches the ovarium surface both in A. chinensis var. deliciosa (Fig. 2) and A. chinensis var. chinensis (Fig. 3). Psa can colonize the outer surfaces of the style by multiplying among the papillae and invading the stylar groove
(Figs. 2b, c and 3d). However, it can also move along the style without a direct colonization of the stylar groove (Fig. 3e, f). Moreover, when bacteria establish an endophytic population, they can penetrate the conductive stylar tissue and move along the tracheids (Supplementary Fig. S2). On the ovarium surface, high pathogen populations were observed especially in $A$. chinensis var. chinensis (Fig. 1). In addition, penetration into the ovarium from the style has also been found (Fig. 2d, e). 

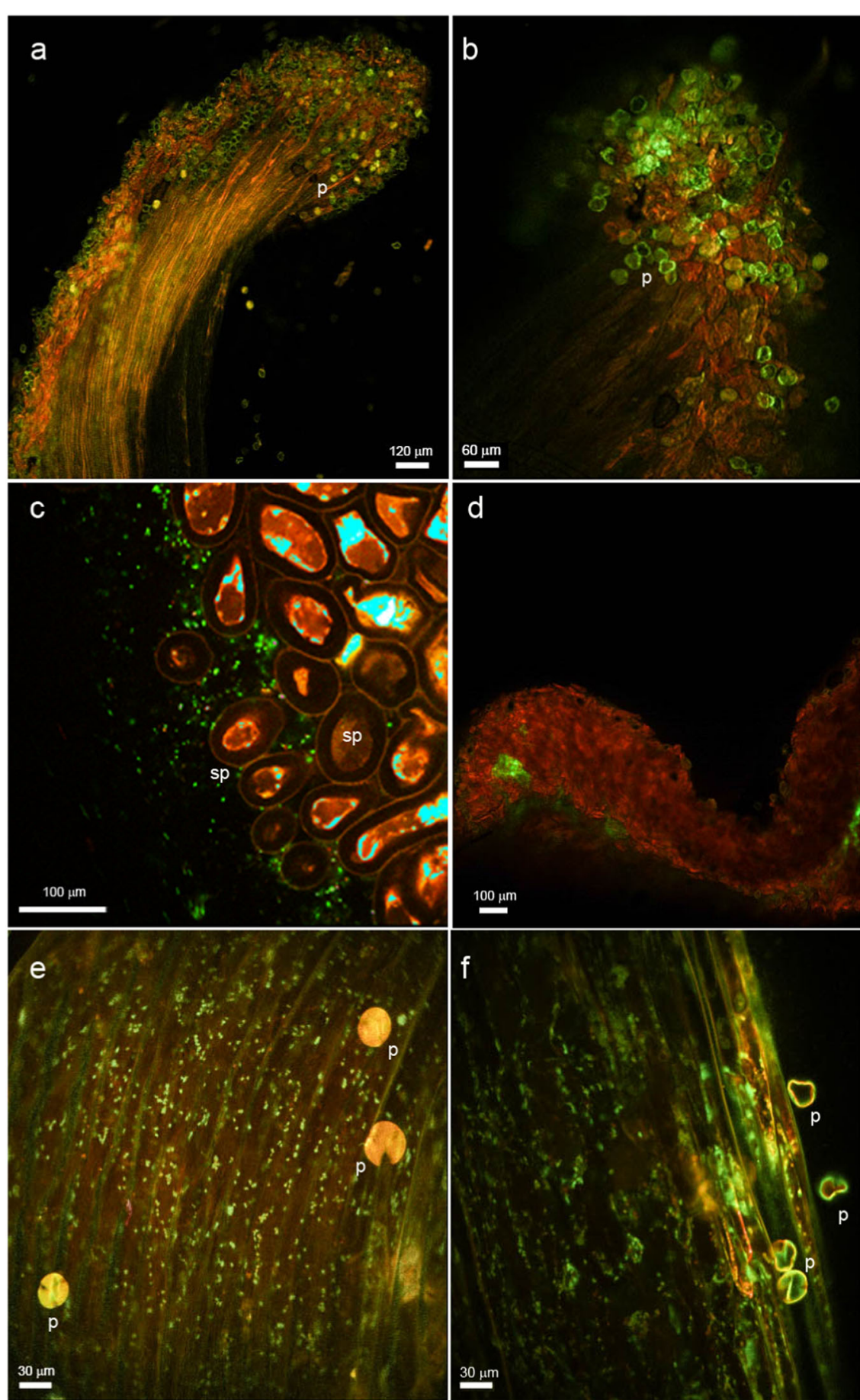

Fig. 3 Confocal laser scanning (CLS) micrographs showing epiphytic colonization of kiwifruit (Actinidia chinensis var. chinensis) pistils by Pseudomonas syringae pv. actinidiae expressing a green fluorescent protein (CFBP7286-GFPuv) after pollination of the flowers with contaminated pollen. Photographs were taken between 24 and $36 \mathrm{~h}$ after inoculation. a Actinidia chinensis var. chinensis healthy stigma. Pollen grains $(p)$ are visible and characterized by a green-yellow fluorescence emission. $\mathbf{b}$ Magnification of Actinidia chinensis var. chinensis stigma pollinated by Psa-contaminated pollen (p). The bright green fluorescent signal is due to CFBP7286-GFPuv. c Actinidia chinensis var. deliciosa stigma colonized by CFBP7286-GFPuv. Bright green rods represent single Psa cells. The brown-red, spherical structures are stigmatic papillae (sp). d Actinidia chinensis var. deliciosa stylar furrow heavily colonized by the pathogen. e, f Actinidia chinensis var. chinensis styles colonized by CFBP7286-GFPuv. Each green rod is a single pathogen cell. Pollen grains (p) show a roughly spherical shape and yellow fluorescence. Bar measure is reported in each panel 


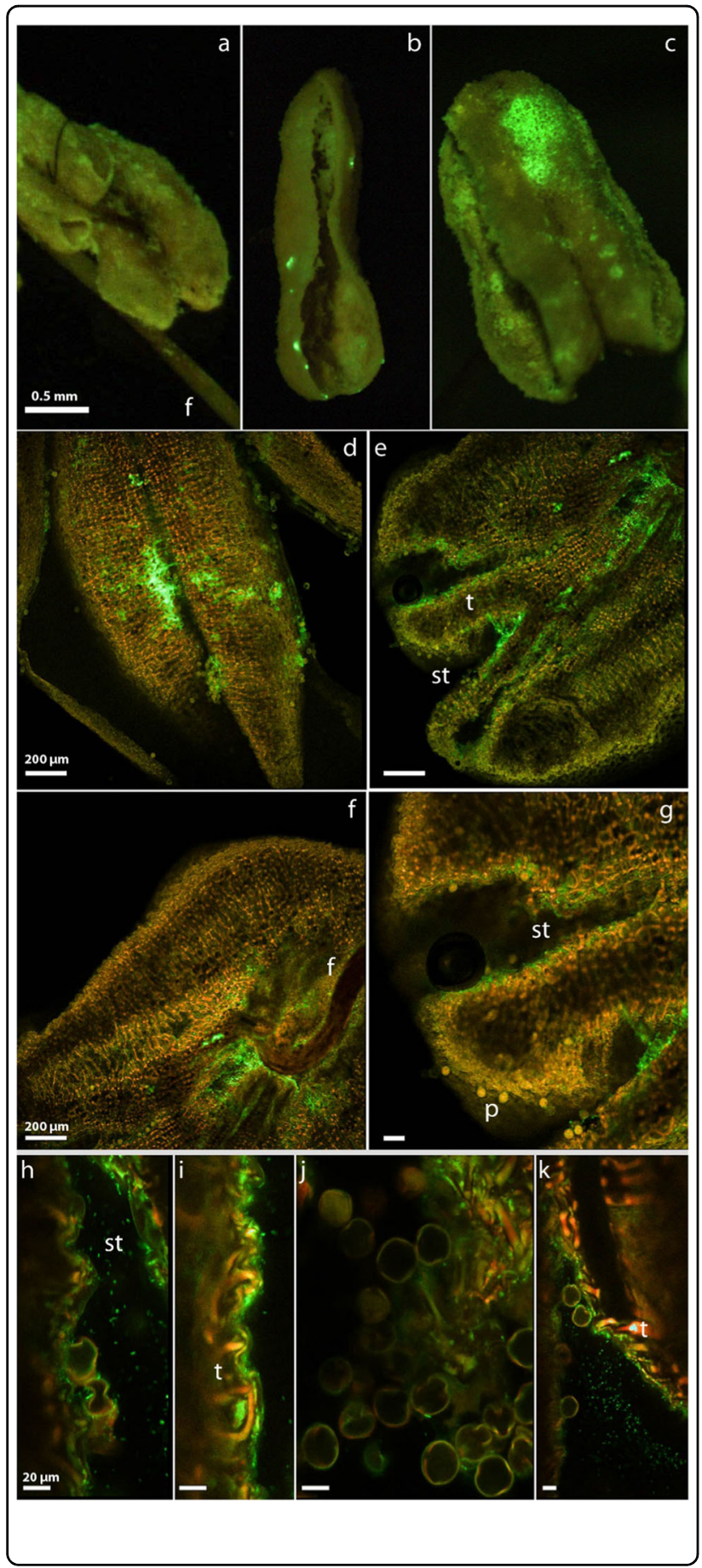

\section{Growth of Psa on pollen and pollinated flowers}

The infection of anthers, even though not supporting higher pathogen populations than other tissues, resulted in contamination of pollen grains (Figs. 1c, d and 4). Anther colonization was often scattered, with small and dispersed areas of each anther colonized by the bacterium, possibly indicating an external, stochastic source of inoculum (Fig. 4b, c). In other cases, Psa colonization
Fig. 4 Colonization of anther and pollen grains of $A$. chinensis sp by Pseudomonas syringae pv. actinidiae expressing a green fluorescent protein (CFBP7286-GFPuv). Fluorescent

steromicroscope $(\mathbf{a}-\mathbf{c})$ and confocal laser scanning $(\mathbf{f}-\mathbf{k})$ photographs of Actinidia chinensis var. chinensis anthers colonized by Pseudomonas syringae pv. actinidiae expressing a green fluorescent protein (CFBP7286-GFPuv). Inoculation was performed by spraying flowers with a suspension of CFBP7286-GFPuv cells. Photographs were taken $48 \mathrm{~h}$ after inoculation. a Healthy anther. The faint yellow-green signal is due to the natural fluorescence of pollen. After pollination of the flowers with contaminated pollen. $\mathbf{b}$ Dehiscent anthers showing epiphytic punctiform colonies of CFBP7286-GFPuv.

c Anther with epiphytic aggregated colonies of CFBP7286-GFPuv. d-g Dehiscent anthers endophytically colonized by CFBP7286-GFPuv. The bacterial colonization of the endotecium is visible at dehiscence when pollen sacks open (d). The tapetum (t), which is the tissue responsible for pollen nutrition and maturation, is highly colonized by the pathogen (e). $\mathbf{f}$ The focus of infection is concentrated at the filament $(\mathbf{f})$, suggesting that the pathogen reached the anthers by endophytic migration along vascular bundles. Stomia (st) are visible. $\mathbf{h}-\mathbf{k}$ Magnification of a stomium showing pollen grains colonized by bacterial cells $(\mathbf{h}, \mathbf{j})$. i Collapsed cells of the tapetum (t) with extra- and endocellular colonization by CFBP7286-GFPuv. In all micrographs, each bright green, rod-shaped structure is a single CFBP7286-GFPuv cell. Bar measure is reported in each panel

becomes visible only after anther dehiscence suggesting a possible internal infection of the anther via pathogen systemic migration along the filament (Fig. 4f). Whenever pollen contamination was observed, the infection of tapetum was also found (Fig. 4g-i). At dehiscence, infected anthers released in the stroma both contaminated pollen grains and free Psa cells (Fig. 4g, h, k). Only a small number of pollen grains were contaminated by Psa cells. In all these cases, Psa was found associated with the pollen grain surface (Fig. $4 \mathrm{~h}-\mathrm{j}$ ). Infection of pollen grains (i.e., penetration of Psa into the microgametophytes) was never observed.

When spray-inoculated at bud break, before flower development, $A$. chinensis var. chinensis male vines produced infected anthers in $(3 \pm 1.2) \%$ of flowers.

Psa was able to survive on pollen grains (Fig. 5a) for at least 5 days, as confirmed by microscopical observation. After the pollination of A. chinensis var. chinensis flowers with infected pollen, Psa initially colonized the stigma and, thereafter, all the floral tissues, reaching the stalk in less than 10 days (Fig. 5b).

Following the exposure of healthy A. chinensis var. chinensis plants to infected male vines, the natural inoculation via contaminated pollen led, in 10 days, to $100 \%$ of contaminated flowers with $(48 \pm 12) \%$ of them resulting in systemic invasion of the plant with an average endophytic Psa population of $10^{4} \mathrm{cfu} \mathrm{g}^{-1} \mathrm{FW}$.

In $A$. chinensis var. deliciosa, natural inoculation by contaminated pollen resulted in $(44 \pm 18) \%$ of flowers harboring an epiphytic Psa population, whereas (25 \pm $13) \%$ of flower infections led to systemic invasion. 

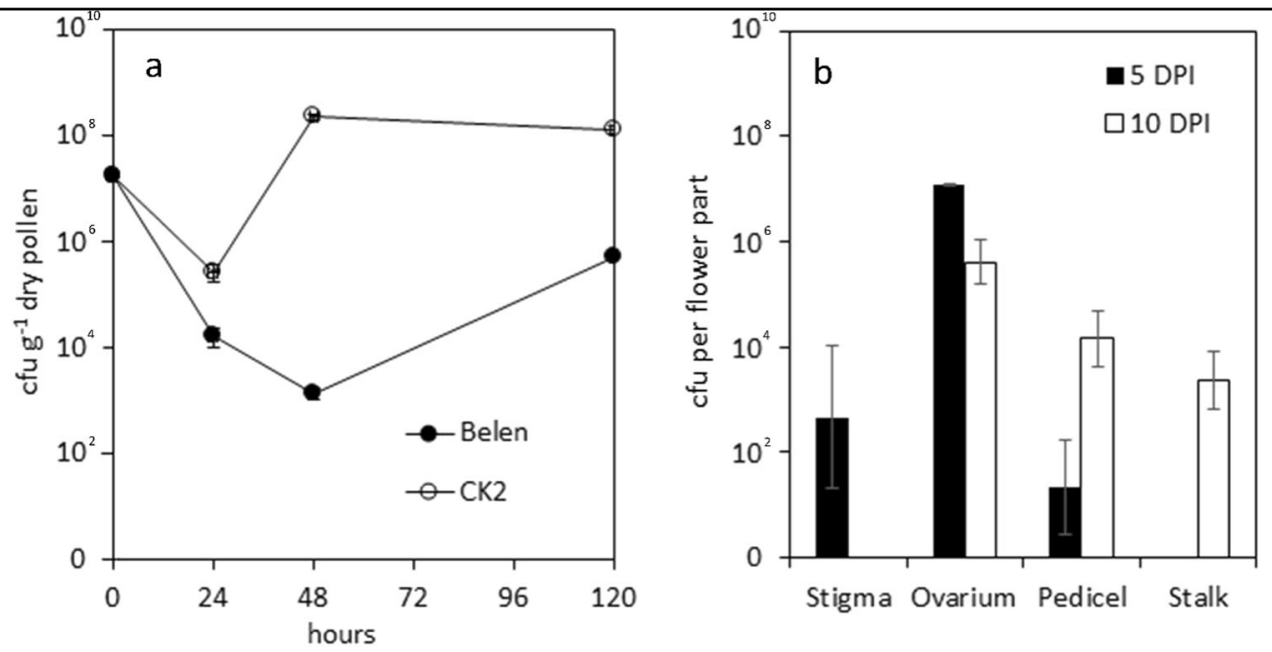

Fig. 5 Pseudomonas syringae pv. actinidiae (Psa) persistence on pollen of $A$. chinensis var chinensis and pollen mediated colonization of different female flower organs. a Survival of Pseudomonas syringae pv. actinidiae (Psa) on pollen from Actinidia chinensis var. chinensis (cvs. Belen and CK2) ( $n=6$ for each time point, per cultivar). b Bacterial population on female A. chinensis var. chinensis flower parts, assessed 5 ( $n=9)$ and 10 $(n=6)$ days post inoculation (DPI) with Psa-contaminated pollen. Standard error is shown

Table 1 Average Pseudomonas syringae pv. actinidiae (Psa) populations in several tissues of Actinidia chinensis var. chinensis, expressed in log (cfu $\mathrm{g}^{-1}$ plant tissue), 4 months after inoculation of a single flower with contaminated pollen

\begin{tabular}{lllll}
\hline & \multicolumn{2}{l}{ Psa population, log (cfu g $\mathbf{- 1}^{-1}$ plant tissue) } & \\
\cline { 2 - 5 } & Apex (100\%) & Graft point (75\%) & Rootstock (75\%) & Roots (75\%) \\
\hline Naturally contaminated pollen $\left(4.1 \times 10^{4} \mathrm{cfu} \mathrm{g}^{-1}\right)$ & $2.9 \pm 1.4$ & $5.4 \pm 1.8$ & $7.6 \pm 1.4$ & $6.9 \pm 0.6$ \\
Experimentally contaminated pollen $\left(10^{6} \mathrm{cfu} \mathrm{g}^{-1}\right)$ & $5.7 \pm 2.0$ & $5.3 \pm 2.7$ & $5.5 \pm 2.7$ & $5.0 \pm 2.6$ \\
\hline
\end{tabular}

The pathogen migrated systemically in all infected plants (Disease Incidence $=100 \%$ ). The relative incidence of Psa in the different plant organs is reported in brackets. Standard error is shown $(n=6)$

\section{Systemic colonization of plant tissues after pollen-} mediated inoculation

After the growth on stigma and stylar furrow, which offers a nourishing and protected environment, Psa established an endophytic population inside the style (Supplementary Fig. S2 and Fig. 5) and the ovarium (Figs. 2 and 5). In particular, Psa was localized at the conjunction between the conductive stylar tissue and the central placenta, thus suggesting the penetration of the ovarium via migration inside the style. Penetration via nectarthodes was not observed in these experiments. Once inside the ovarium, Psa can colonize the vascular bundles, which may lead to the migration to flower pedicels. The migration of Psa via flower pedicel was observed by microscopical analysis (Fig. 2f) and resulted in systemic infection of the plant (Fig. 5b). Leaf spots were observed 2 months after flower inoculation.

In rare cases, highly infected female flowers produced droplets of bacterial exudate emerging with the nectar. Under high humidity conditions, the bacterial exudates dropped along the pedicel till reaching the abscission zone which, at flower drop, may represent a possible entry point.

Four months after inoculation of a single flower, the bacterium could be found in all the tissues (canes, grafting point, rootstock, roots), independent of the source of pollen infection (natural or experimental) and its bacterial load (Table 1), showing both acropetal and basipetal migration.

In the same plants, all fruit dropped within 75 days after flowering, when the fruit diameter was below $40 \mathrm{~mm}$. In contrast, control (healthy) plants only dropped $21 \%$ of their fruit load in 84 days (end of monitoring period).

\section{Flower blight incidence and contamination of pollinators in infected orchards}

On $A$. chinensis var. chinensis female flower samples showing browning symptoms, Psa incidence was $82 \%$, with an average population of $3.3 \pm 1.6 \times 10^{8} \mathrm{cfu}$ per flower. In contrast, $17 \%$ of these flowers were infected with either $P$. syringae pv. syringae or $P$. viridiflava. Psa was also found on $40 \%$ of asymptomatic flowers, but with 
Table 2 Incidence of male and female flower contamination and Pseudomonas syringae pv. actinidiae (Psa) average population in Actinidia chinensis var. chinensis and A. chinensis var. deliciosa (100 flowers per each variety) collected from symptomatic plants

\begin{tabular}{|c|c|c|c|c|c|}
\hline & \multirow[t]{2}{*}{ Category } & \multicolumn{2}{|l|}{ Flowers } & \multicolumn{2}{|l|}{ Pollen } \\
\hline & & Incidence (\%) & Population (cfu per flower) & Incidence (\%) & Population ( $\mathrm{cfu} \mathrm{g}^{-1}$ ) \\
\hline \multicolumn{6}{|l|}{ Male } \\
\hline \multirow[t]{2}{*}{ A. chinensis var. chinensis } & Closed & $71 b^{*}$ & $(2.9 \pm 0.8) \times 10^{4}$ & $5 a$ & $(1.9 \pm 0.9) \times 10^{2}$ \\
\hline & Open & $56 a^{*}$ & $(2.8 \pm 0.7) \times 10^{8}$ & $10 a^{*}$ & $(2.6 \pm 1.1) \times 10^{2}$ \\
\hline \multirow[t]{2}{*}{ A. chinensis var. deliciosa } & Closed & $56 \mathrm{a}$ & $(2.9 \pm 1.5) \times 10^{4}$ & $4 \mathrm{a}$ & $(9.9 \pm 2.5) \times 10^{1}$ \\
\hline & Open & $100 \mathrm{~b}$ & $(7.8 \pm 4.4) \times 10^{4}$ & $80 \mathrm{~b}$ & $(2.5 \pm 0.7) \times 10^{2}$ \\
\hline \multicolumn{6}{|l|}{ Female } \\
\hline \multirow[t]{2}{*}{ A. chinensis var. chinensis } & Asymptomatic & $40 \mathrm{a}$ & $(5.9 \pm 1.2) \times 10^{5}$ & - & - \\
\hline & Symptomatic & $82 \mathrm{~b}$ & $(3.3 \pm 1.6) \times 10^{8}$ & & \\
\hline \multirow[t]{2}{*}{ A. chinensis var. deliciosa } & Asymptomatic & $36 a$ & $(1.5 \pm 0.9) \times 10^{5}$ & - & - \\
\hline & Symptomatic & $73 b$ & $(2.7 \pm 1.7) \times 10^{8}$ & & \\
\hline
\end{tabular}

Flowers were grouped according to either their symptomatology (asymptomatic or browning) or phenological stage (closed or open). Standard error is shown. Incidence values followed by different letters are significantly different according to $Z$-test $(P<0.05)$. Lowercase letters indicate difference between closed and open or asymptomatic and symptomatic flowers, *indicates significant differences between varieties for same kind of flowers

Table 3 Pseudomonas syringae pv. actinidiae (Psa) incidence and average population on bumblebees (Bombus terrestris) and harvested pollen samples collected during kiwifruit flowering over 3 years (2014-2016)

\begin{tabular}{|c|c|c|c|c|}
\hline \multirow[t]{2}{*}{ Year } & \multicolumn{2}{|c|}{ Bumblebees } & \multicolumn{2}{|l|}{ Pollen } \\
\hline & $\begin{array}{l}\text { Incidence } \\
(\%)\end{array}$ & $\begin{array}{l}\text { Population } \\
\text { (cfu per insect }^{-1} \text { ) }\end{array}$ & $\begin{array}{l}\text { Incidence } \\
(\%)\end{array}$ & $\begin{array}{l}\text { Population } \\
\left(\mathrm{cfu} \mathrm{g}^{-1}\right)\end{array}$ \\
\hline 2014 & 20 & $(4.3 \pm 0.7) \times 10^{3}$ & 40 & $(3.4 \pm 0.1) \times 10^{2}$ \\
\hline 2015 & 50 & $(3.3 \pm 2.3) \times 10^{3}$ & 50 & $(5.9 \pm 0.9) \times 10^{4}$ \\
\hline 2016 & 20 & $(6.7 \pm 5.0) \times 10^{2}$ & 30 & $(1.2 \pm 0.0) \times 10^{4}$ \\
\hline
\end{tabular}

The experiment was performed in a commercial Actinidia chinensis var. chinensis orchard. Bumblebees capture was performed during 3 consecutive days, and, in each day, ten individuals were captured at return to the beehive $(n=30)$. Standard error is shown

an average population 1000 times lower than in symptomatic flowers (Table 2). The Psa incidence and epiphytic population were substantially similar between $A$. chinensis var. chinensis and var. deliciosa female flowers (Table 2).

On male flowers, anthers (from closed flowers) and pollen (from open ones) were separately analyzed and Psa was detected in $56 \%$ and $100 \%$ of the open flowers in $A$. chinensis var. chinensis var. deliciosa, respectively (Table 2). In closed flowers, the presence of Psa is limited to the outer side of the flower, while the anthers are generally not reached by the bacterium (Table 2). However, Psa was found in the anthers or pollen with a significant bacterial population (average $2.2 \pm 1.3 \times 10^{2} \mathrm{cfu}$ $\left.\mathrm{g}^{-1}\right)$, independently of flower phenological stage and presence of symptoms. This pollen was characterized by a very low viability, in no case higher than $5 \%$.
During the 3 years of monitoring (2014-2016) of infected A. chinensis var. deliciosa orchards, about $20 \%$ of the worker bumblebees were contaminated with Psa (Table 3). On these individuals, the average Psa population in the different years was $2.8 \pm 2.6 \times 10^{3}$ cells per insect. Significant Psa populations were also detected on the pollen harvested by bumblebees and stored in the hive (Table 3). About $40 \%$ of the pollen samples were contaminated by Psa (Table 3 ). On experimentally inoculated honeybee bodies, wax, and pollen maintained in a honeybee hive, viable Psa units were not detected $48 \mathrm{~h}$ after inoculation.

\section{Discussion}

Colonization of flowers by Psa

Psa was able to densely colonize flowers. The styles hosted the highest populations $\left(\geq 10^{5} \mathrm{cfu}\right)$, possibly 
because of nutrients and moisture secreted by the stigma. Male flowers are less conducive for Psa growth.

A. chinensis var. chinensis female flowers supported more uniform bacterial populations in the different flower parts, compared to A. chinensis var. deliciosa (Fig. 1). Since Psa attains similar populations on the styles of both A. chinensis varieties, the chemical composition of flower secretions is probably equally favorable to Psa growth. Morphological differences may explain the more widespread colonization of Psa on A. chinensis var. chinensis. In this variety, the denser trichome coverage on leaves, shoots, and flowers may promote moisture preservation, which is a key factor for flower-colonizing bacterial communities ${ }^{40}$. Furthermore, trichomes may also represent an entry point for the pathogen ${ }^{13}$.

Contamination of male flowers also resulted in the production of contaminated pollen. The contamination is substantially lower in closed than in open flowers, suggesting that pollen is generally contaminated by external inoculum sources (e.g., rain, wind, insects). However, contaminated pollen was also found in $5-10 \%$ of the closed flowers, where an external source of contamination can be excluded. Moreover, the experiment performed by inoculating, before flowering, male vines with CFBP7286GFPuv confirmed this finding. Therefore, a systemic acropetal migration of Psa to anthers from other flower tissues could be responsible for this result. Nonetheless, an epiphytic contamination at bud break of developing sepals and petals and the migration of the pathogen to the inner tissues of flowers till reaching the anthers cannot be completely excluded. Finally, Psa populations on pollen were independent to the Psa population on flowers.

The apparently different incidence of Psa in open $A$. chinensis var. chinensis and $A$. chinensis var. deliciosa male flowers and pollen is probably due to a different disease pressure inside the orchards and to the different climatic conditions at flowering. In fact, $A$. chinensis var. deliciosa flowering takes place approximately 20 days after A. chinensis var. chinensis, when the climatic conditions (higher temperatures, lower relative humidity, lower occurrence of rainfall, and leaf wetting) may be less conducive for epiphytic Psa growth.

\section{Invasion of host tissues}

Unlike fungal pathogens, bacteria are generally unable to actively penetrate plant tissues, and rely on wounds and natural openings, such as stomata, lenticels, and nec$\operatorname{tarthodes}^{41}$ to access the host's apoplast. Flowers have been previously suggested to be among the major entry points for Psa, although no experimental evidence was available $^{42-44}$. In this view, flower infection would lead to systemic invasion of the whole plant.

In this work, high bacterial populations, showing that Psa was multiplying, were found on stigmata, suggesting that the stigma is a strong candidate for initial flower infection. Supporting this view, the direct dip-inoculation of stigmata caused the highest pathogen population within the flower pedicel. Subsequently, the bacterium moves along the stylar furrow and stylar connections toward the ovarium, where further multiplication and penetration to the apoplast may occur. The ovarium surface is, in fact, rich in trichomes and represents a suitable environment for the pathogen. In contrast, direct penetration from the calyx into the ovarium is unlikely, since there are no natural connections between these organs.

Bacterial plant pathogens may have an obligate infection path through flower tissues. E. amylovora, for instance, migrates along the style and the stylar furrow ${ }^{24}$ before accessing the ovary tissue. In contrast, Psa can also penetrate into the apoplast from the stylar surface (Supplementary Fig. S2). In this case, the bacterium was found in the conductive tissues, but not in the tracheids. This observation may suggest that the pathogen is unable to move through the xylem sieves of small vessels.

Further migration to the flower pedicel and flower stalk has also been observed. The invasion of flower stalks eventually leads to systemic infection.

Male flowers collected in the field may also be infected by the pathogen, with similar susceptibility and symptomatology to female flowers. However, the infection path through their tissues is not as clear as in female flowers. Since the presence of Psa in the flower stalk (Fig. 1) may be due to accidental contamination of the stalk itself during the experimental inoculation, the systemic penetration of the bacterium via male flowers still needs further verification.

\section{Ecological significance of pollen-mediated Psa spread and role of pollinators}

Closed, asymptomatic flowers collected from symptomatic plants showed to be infected with Psa and to produce contaminated pollen, thus demonstrating that Psa may endophytically migrate to developing flowers in infected plants, leading to the contamination of anthers and the production of contaminated pollen. Paradoxically, Psa was more frequently found (although with lower populations) in asymptomatic flowers, and on pollen derived from asymptomatic flowers, than on symptomatic ones. It may be suggested that symptomatic flowers drop from the vine as its metabolism is no longer effective. This hypothesis is further supported by the observation that, in controlled conditions, all flowers infected via contaminated pollen dropped within 75 days after pollination.

Evidence of pollen contamination with Psa was previously provided ${ }^{32,36}$. However, the attempts to establish the ecological significance of pollen-vectored Psa in the 
development of bacterial canker ${ }^{33,37}$ only led to circumstantial evidence, either because of the artificial conditions of laboratory experiments, or because of the inability to track the source of infection and the bacterium during the various stages of pathogenesis in field conditions. Crucial information was missing about ecological aspects (such survival on flower parts and pathogen infection pathways), presumably affecting the chance of pollen-mediated Psa spread in field conditions.

Our research aimed to fill the information gap between flower inoculation and whole plant colonization, by visualizing the infection path exploited by Psa to penetrate the host plant's apoplast. Our observations strongly suggest pollen-mediated flower contamination as one of the main infection pathways in field conditions.

Psa was found to survive on honeybees and in hives ${ }^{45}$. However, the importance of honeybee-mediated infection in field conditions is not clear. In this work, limited survival of Psa was observed in hive conditions; notably, the initial population in each sample had little influence on the survival time, suggesting that hive temperature $\left(35^{\circ} \mathrm{C}\right)$ and/or antimicrobial compounds, naturally present on the biological samples taken from the hive, may prevent Psa growth ${ }^{34}$. In addition to honeybees, significant Psa populations were also found on bumblebees foraging in infected fields. Overall, although direct evidence for insect-mediated Psa vectoring is still missing, the bacterial populations in hives and on insects are compatible with those employed for successful plant inoculation by hand-pollination (approx. $10^{4} \mathrm{cfu} \mathrm{g}^{-1}$ pollen), but only for a short time after contamination. Thus, pollinators may be involved in short-range, secondary Psa spread.

\section{Conclusions}

This work demonstrates that flower tissues, and particularly stigmata, are crucial sites for Psa growth and penetration into the host tissues. Moreover, our work reports the first evidence of production of contaminated pollen by asymptomatic closed male flowers from infected plants and the role of pollen-mediated dispersal of a bacterial plant pathogen in natural conditions. Thus, plant protection strategies should consider the cultural practices involving flowers (for instance, inspection of pollendonor plants, sanitation of pollinators, or the use of biological control agents competing with Psa in the floral niche) to minimize the risk of disease.

\section{Acknowledgements}

The work was funded by the European Union's Seventh Framework Program for research, technological development, and demonstration under grant agreement no 613678 (DROPSA-Strategies to develop effective, innovative, and practical approaches to protect major European fruit crops from pests and pathogens). Dr. Giovanni Fiori is acknowledged for technical support.

\section{Author details}

${ }^{1}$ Department of Agricultural and Food Sciences - DISTAL, Alma Mater Studiorum — University of Bologna, viale Fanin 44, 40127 Bologna, Italy. ${ }^{2}$ ZESPRI GLOBAL Supply, 400 Maunganui Road, Mount Maunganui, New Zealand. ${ }^{3}$ Consiglio per la Ricerca e la Sperimentazione in Agricoltura-Genomics Research Centre, via S. Protaso 302, 29017 Fiorenzuola d'Arda, Italy

\section{Conflict of interest}

The authors declare that they have no conflict of interest.

Supplementary Information accompanies this paper at https://doi.org/ 10.1038/s41438-018-0058-6.

Received: 15 November 2017 Revised: 29 May 2018 Accepted: 4 June 2018 Published online: 01 November 2018

\section{References}

1. Vanneste, J. L. Recent progress on detecting, understanding and controlling Pseudomonas syringae pv. actinidiae: a short review. N. Z. Plant Prot. 66, 170-177 (2013).

2. Donati, I. et al. New insights on the bacterial canker of kiwifruit (Pseudomonas syringae pv. actinidiae). J. Berry Res. 4, 53-67 (2014).

3. Greer, G. \& Saunders, C. The costs of Psa-V to the New Zealand kiwifruit industry and the wider community. In: Report to kiwifruit VineHealth. Lincoln University press, New Zealand: Agribusiness and Economics Research Unit, 2-9 (2012).

4. Balestra, G. M., Renzi, M. \& Mazzaglia, A. First report of bacterial canker of Actinidia deliciosa caused by Pseudomonas syringae pv. actinidiae in Portugal. New Dis. Rep. 22, 10 (2010).

5. Koh, Y. J., Kim, G. H., Jung, J. S., Lee, Y. S. \& Hur, J. S. Outbreak of bacterial canker on Hort16A (Actinidia chinensis Planchon) caused by Pseudomonas syringae pv. actinidiae in Korea. N. Z. J. Crop Hort. Sci. 38, 275-282 (2010).

6. Vanneste, J. L. et al. First report of Pseudomonas syringae pv. actinidiae, the causal agent of bacterial canker of kiwifruit in France. Plant Dis. 95, 1311 (2011).

7. Scortichini, M. Occurrence of Pseudomonas syringae pv. actinidiae on kiwifruit in Italy. Plant Pathol. 43, 1035-1038 (1994).

8. Balestra, G. M., Mazzaglia, A., Quattrucci, A., Renzi, M. \& Rossetti, A. Current status of bacterial canker spread on kiwifruit in Italy. Aust. Plant Dis. Notes $\mathbf{4}$, 34-36 (2009).

9. Ferrante, P. \& Scortichini, M. Identification of Pseudomonas syringae pv. actinidiae as causal agent of bacterial canker of yellow kiwifruit (Actinidia chinensis Planchon) in Central Italy. J. Phytopathol. 157, 768-770 (2009).

10. Spadaro, D. et al. The arrival of kiwifruit canker in Piedmont]. Inf. Agrar. 66, 58-59 (2010).

11. Everett, K. R. et al. First report of Pseudomonas syringae pv. actinidiae causing kiwifruit bacterial canker in New Zealand. Australas. Plant Dis. Notes 6, 67-71 (2011).

12. Vanneste, J. L. The scientific, economic, and social impacts of the New Zealand outbreak of bacterial canker of kiwifruit (Pseudomonas syringae pv. actinidiae). Ann. Rev. Phytopatology 55, 377-399 (2017).

13. Spinelli, F., Donati, I., Vanneste, J. L., Costa, M. \& Costa, G. Real time monitoring of the interactions between Pseudomonas syringae pv. actinidiae and Actinidia species. Acta Hortic. 913, 461-465 (2011).

14. Ferrante, $\mathrm{P}$. et al. The importance of the main colonization and penetration sites of Pseudomonas syringae pv. actinidiae and prevailing weather conditions in the development of epidemics in yellow kiwifruit, recently observed in central Italy. J. Plant Pathol. 94, 455-461 (2012).

15. Young, J. M., Cheesmur, G. J., Welham, F. V. \& Henshall, W. R. Bacterial blight of kiwifruit. Ann. Appl. Biol. 112, 91-105 (1988).

16. Everett, K. R. \& Henshall, W. R. Epidemiology and population ecology of kiwifruit blossom blight. Plant Pathol. 43, 824-830 (1994).

17. Balestra, G. B. \& Varvaro, L. Pseudomonas syringae pv. syringae causal agent of disease on floral buds of Actinidia deliciosa (A. Chev) Liang et Ferguson in Italy. J. Phytopathol. 145, 375-378 (1997).

18. Rossetti, A. \& Balestra, G. M. Pseudomonas syringae pv. syringae on kiwifruit plants: epidemiological traits and its control. In: Fatmi M. et al. (eds) Pseudomonas syringae pathovars and related pathogens - Identification, Epidemiology and Genomics. Springer, Dordrecht, 65-68 (2008). 
19. Ark, P. A. Further evidence of pollen dissemination of walnut blight. Phytopathology 34, 329-334 (1944).

20. Ercolani, G. L. [Individuazione di Xanthomonas juglandis (Pierce) Dowson in Emilia]. English, Abstract, Conclusion and Figure Captions. Phytopathol. Mediterr. 2, 1-10 (1962).

21. Wilson, M., Sigee, D. C. \& Epton, H. A. S. Enwinia amylovora infection of hawthorn blossom: I. The anther. J. Phytopathol. 127, 1-14 (1989).

22. Mansvelt, E. L. \& Hattingh, M. J. Scanning electron microscopy of pear blossom invasion by Pseudomonas syringae pv. syringae. Can. J. Bot. 65, 2523-2529 (1987).

23. Wilson, M., Sigee, D. C. \& Epton, H. A. S. Enwinia amylovora infection of hawthorn blossom: II. The stigma. J. Phytopathol. 127, 15-28 (1989).

24. Spinelli, F., Ciampolini, F., Cresti, M., Geider, K. \& Costa, G. Influence of stigmatic morphology on flower colonization by Erwinia amylovora and Pantoea agglomerans. Eur. J. Plant Pathol. 113, 395-405 (2005).

25. Johnson, K. B., Stockwell, V. O., Burgett, D. M., Sugar, D. \& Loper, J. E. Dispersal of Enwinia amylovora and Pseudomonas fluorescens by honey bees from hives to apple and pear blossoms. Phytopathology 83, 478-484 (1993).

26. McArt, S. H., Koch, H., Irwin, R. E. \& Adler, L. S. Arranging the bouquet of disease: floral traits and the transmission of plant and animal pathogens. Ecol. Lett. 17, 624-636 (2014).

27. Howpage, D., Spooner-Hart, R. N. \& Vithanage, V. Influence of honey bee (Apis mellifera) on kiwifruit pollination and fruit quality under Australian conditions. N.Z. J. Crop Hortic. Sci. 29, 51-59 (2001).

28. Testolin, R., Vizzotto, G. \& Costa, G. Kiwifruit pollination by wind and insects in Italy. N.Z. J. Crop Hortic. Sci. 19, 381-384 (1991).

29. Howpage, D., Vithanage, V. \& Spooner-Hart, R. Pollen tube distribution in the kiwifruit (Actinidia deliciosa A. Chev. C. F. Liang) pistil in relation to its reproductive process. Ann. Bot. (Lond.) 81, 697-703 (1998).

30. Gonzalez, M. V., Coque, M. \& Herrero, M. Papillar integrity as an indicator of stigmatic receptivity in kiwifruit (Actinidia deliciosa). J. Exp. Bot. 46, 263-269 (1995).

31. Hopping, M. E. \& Jerram, E. M. Supplementary pollination of tree fruits. II. Field trials on kiwifruit and Japanese plums. N.Z. J. Agric. Res. 23, 517-521 (1980).

32. Vanneste, J. L. et al. Detection of Pseudomonas syringae pv. actinidiae in kiwifruit pollen samples. N.Z. Plant Prot. 64, 246-251 (2011).

33. Stefani, E. \& Giovanardi, D. Dissemination of Pseudomonas syringae pv. actinidiae through pollen and its epiphytic life on leaves and fruits. Phytopathol. Mediterr. 50, 489-496 (2011).
34. Everett, K. R. et al. Heat treatments to kill Pseudomonas syringae pv. actinidiae on contaminated pollen. N.Z. Plant Prot. 65, 8-18 (2012).

35. Biondi, E. et al. Pseudomonas syringae pv. actinidiae detection in kiwifruit plant tissue and bleeding sap. Ann. Appl. Biol. 162, 60-70 (2013).

36. Gallelli, A., Talocci, S., L'Aurora, A. \& Loreti, S. Detection of Pseudomonas syringae pv. actinidiae, causal agent of bacterial canker of kiwifruit, from symptomless fruits and twigs, and from pollen. Phytopathol. Mediterr. 50, 462-472 (2011).

37. Tontou, R., Giovanardi, D. \& Stefani, E. Pollen as a possible pathway for the dissemination of Pseudomonas syringae pv. actinidiae and bacterial canker of kiwifruit. Phytopathol. Mediterr. 53, 333-339 (2014).

38. Sigee, D. C. Bacteria as plant pathogens. In: Bacterial Plant Pathology: Cell and Molecular Aspects. D. C. Sigee, ed. Cambridge University Press, Cambridge. pp. $1-12$.

39. Gallelli, A., Talocci, S., Pilotti, M. \& Loreti, S. Real-time and qualitative PCR for detecting Pseudomonas syringae pv. actinidiae isolates causing recent outbreaks of kiwifruit bacterial canker. Plant Pathol. 63, 264-276 (2014).

40. Pusey, P. L. The role of water in epiphytic colonization and infection of pomaceous flowers by Enwinia amylovora. Phytopathology 90, 1352-1357 (2000).

41. Gimenez-lbanez, S. \& Rathjen, J. P. The case for defence: plant versus Pseudomonas syringae. Microbes Infect. 12, 428-437 (2010).

42. Balestra, G. M. [Use of copper formulations to limit bacterial diseases in kiwifruit. (Speciale Actinidia)]. Riv. di Fruttic. e di Ortofloric. 66, 35-41 (2004).

43. Serizawa, S. \& Ichikawa, T. Epidemiology of bacterial canker of kiwifruit. 2. The most suitable times and environments for infection on new canes. Ann. Phytopathol. Soc. Jpn. 59, 460-468 (1993).

44. Serizawa, S., Ichikawa, T., Takikawa, Y., Tsuyumu, S. \& Goto, M. Occurrence of bacterial canker of kiwifruit in Japan: description of symptoms, isolation of the pathogen and screening of bactericides. Ann. Phytopathol. Soc. Jpn. 55, 427-436 (1989).

45. Pattemore, D. E., Goodwin, R. M., McBrydie, H. M., Hoyte, S. M. \& Vanneste, J. L. Evidence of the role of honey bees (Apis mellifera) as vectors of the bacterial plant pathogen Pseudomonas syringae. Australas. Plant Pathol. 43, 571-575 (2014). 